\title{
El discurso publicitario en la crisis económica: nuevos valores y redes sociales
}

\author{
Araceli CASTELló MARTíneZ \\ Universidad de Alicante \\ araceli.castello@ua.es \\ Irene RAMOS SOLER \\ Universidad de Alicante \\ irene.ramos@ua.es \\ Cristina Del Pino Romero \\ Universidad Carlos III de Madrid \\ cpino@hum.uc3m.es
}

\section{Resumen:}

La coyuntura de crisis afecta al sector publicitario no solo en términos económicos. El auge de los medios no convencionales, el rol activo del destinatario, el aumento de la inversión en Internet y el afán de conectar emocionalmente con el público son otras de las características más relevantes de la comunicación publicitaria actual.

En este contexto, nos encontramos con una nueva tendencia en el discurso publicitario: el interés por narrar historias que afectan directamente al ciudadano, apelando al compromiso con unos valores.

Palabras Clave: crisis; valores; comunicación publicitaria; publicidad emocional; filosofía 2.0.

\section{The advertising speech in the economic crisis: new values and social networks}

\begin{abstract}
:
The current situation regarding to the ecnomic crisis not only affects the advertising industry. The peak of the no conventional media, the active rol of the consumer, the increase of the investment on the Internet and the need to connect emotionally with the target are others of the most notable characteristics of the advertising communication nowadays.

In this context, we are right in front of a new tendency in the advertising speech: the interest for narrating histories that affect directly to the citizen, appealing to the commitment with some values.
\end{abstract}

Key Words: crisis; values; advertising communication; emotional advertising; philosophy 2.0.

\section{Referencia normalizada:}

Castelló Martínez, A.; Ramos Soler, I.; Del Pino Romero, C. (2013) El discurso publicitario en la crisis económica: nuevos valores y redes sociales. Historia y Comunicación Social. Vol. $18 \mathrm{~N}^{\circ}$ Especial Octubre. Págs. 657--672.

Sumario: 1. Introducción. 1.1. La crisis y la Publicidad. 1.2. Valores y Publicidad. 2. Método. 2.1. Metodología e Hipótesis. 3. Resultados. 4. Conclusiones y discusión. 


\section{Introducción}

\subsection{Crisis y publicidad}

Desde 2008, una de las palabras más repetidas en los medios de comunicación es "crisis". En todas sus vertientes y variables, la crisis se ha adueñado de espacios en informativos, en cualquier medio, copando titulares y todo tipo de conversaciones.

Si esta situación ha afectado a la comunicación en general, no menos ha afectado a la comunicación publicitaria. Desde un año antes de la entrada oficial de la crisis en España, el sector publicitario es objeto de un descenso en la inversión que si bien no es la primera vez que se produce - esta recesión es habitual en estos periodos de coyuntura económica- sí es sin duda uno de los descensos más acusados de los últimos tiempos. Hablamos de la crisis que afecta al universo capitalista (Caro, 2009: 9).

Pero, además, esta crisis no sólo afecta a la publicidad en términos cuantitativos, sino que la industria también vive un periodo de cambios profundos en los pilares de la comunicación corporativa y publicitaria, derivados de diversos aspectos:

- Crisis de la publicidad convencional: los medios masivos ya no centran el interés de los anunciantes como ocurriera en un pasado, debido a la saturación publicitaria que les caracteriza. Además, en la actualidad, la multidireccionalidad del mensaje es una realidad incuestionable. A esto se suma la importancia de la segmentación del mensaje, la personalización del mismo y el contar con la integración del mensaje publicitario como una obligación y no como una opción. Las cifras hablan: en 2011, los medios no convencionales representaron el $54,4 \%$ del total, un dato histórico.

- El ciudadano tiene más que nunca la última palabra, que se traduce en la dinámica por la cual lleva a cabo una búsqueda mucho más intensa de alternativas, así como una comparativa de precios y recopilación de información, opiniones y experiencias de otros usuarios, antes de tomar la decisión final de compra.

- El papel predominante de las redes sociales en la era de la digitalización, consideradas en la comunicación empresarial y en la filosofía 2.0, que implica un protagonismo incuestionable del usuario.

Un aspecto de suma relevancia lo encontramos en el afán e interés por establecer una conexión emocional con el público, dentro de este cambio de paradigma en la comunicación publicitaria y empresarial. El discurso publicitario de la crisis económica ha cambiado su esencia y estructura, estando siempre presente en el imaginario colectivo la sombra de la incertidumbre en esta travesía de uno de los momentos más duros de nuestra historia reciente.

Así las cosas, la apuesta ahora es narrar historias que afecten al ciudadano, incidiendo en la importancia del binomio compromiso-valores. De esta forma, el ciudadano se convierte en protagonista principal del mensaje; toma voz a través de la de actores que en campañas de distinta naturaleza, inciden en la empatía, refuerzan 
la identificación y hacen de esta forma que todo lo relativo a la marca, producto o empresa pasen a un plano más secundario.

Ante este panorama, con un receptor mucho más crítico, los anunciantes saben de la desconfianza y el resquemor, así como de una capacidad de decidir nunca antes vista en la historia, y al tiempo, saben que la actual situación supone una coyuntura emocional que predispone positivamente a la recepción de cierto tipo de mensajes, que bien elucubrados, pueden resultar sumamente efectivos en este contexto del estado de ánimo imperante.

Esta es la razón de que comuniquen, por ejemplo, mejoras en el precio (ofertas, descuentos, rebajas, etc.) así como la calidad de sus productos como reacción frente a la crisis. De la misma forma, también se anuncian mostrando su faceta más amable, aquella en la que se puede ver lo que hacen de bueno por y para la sociedad, en un ejercicio de comunicación de su responsabilidad social corporativa, en donde la llamada a la bonhomía de la ciudadanía y a valores positivos es una constante.

Fernández, Alameda y Martín (2011) identifican una tendencia a emplear una estrategia publicitaria con valores de posicionamiento relacionados con la crisis basados en lo intangible, con una línea emocional y de relación con el consumidor:

En esta línea, la comunicación está basada más en la emoción y en los sentimientos, busca la vinculación afectiva entre la marca y el consumidor, mediante contenidos dirigidos a sus sentidos (alegría, felicidad, posibilidades, anhelos, sueños...). Las historias reales de la gente ganan terreno frente a los mensajes anodinos de productos a los que nos tiene acostumbrados la publicidad (Fernández, Alameda y Martín, 2011:135).

Uno de los ejemplos más claros en donde el positivismo no deja lugar a dudas, lo tenemos en Coca-Cola y su llamada a la felicidad como valor positivo, valor éste universal, atemporal y desprovisto de connotaciones que en principio tengan que ver con la situación de la economía. De esta forma, en 2009 la marca emitía el anuncio "Estás aquí para ser feliz" en el que, en un contexto de crisis y pesimismo, se planteaba la siguiente pregunta: "¿qué le dirías a alguien que ha venido al mundo en un momento como este?" [1].

En la misma línea aunque de naturaleza diferente, con motivo de la Eurocopa 2012, la marca de refrescos también difundía otro spot en el que, tras presentarse una serie de malas noticias, se destacaban otros acontecimientos o acciones de carácter positivo que habían tenido lugar en España, bajo la idea de que "Vamos a demostrarle a Europa de lo que somos capaces cuando estamos juntos" y con el uso de la etiqueta en Twitter \#razonesparacreer (imagen 1): 
Imagen 1. Spot de Coca-Cola \#razonesparacreer.

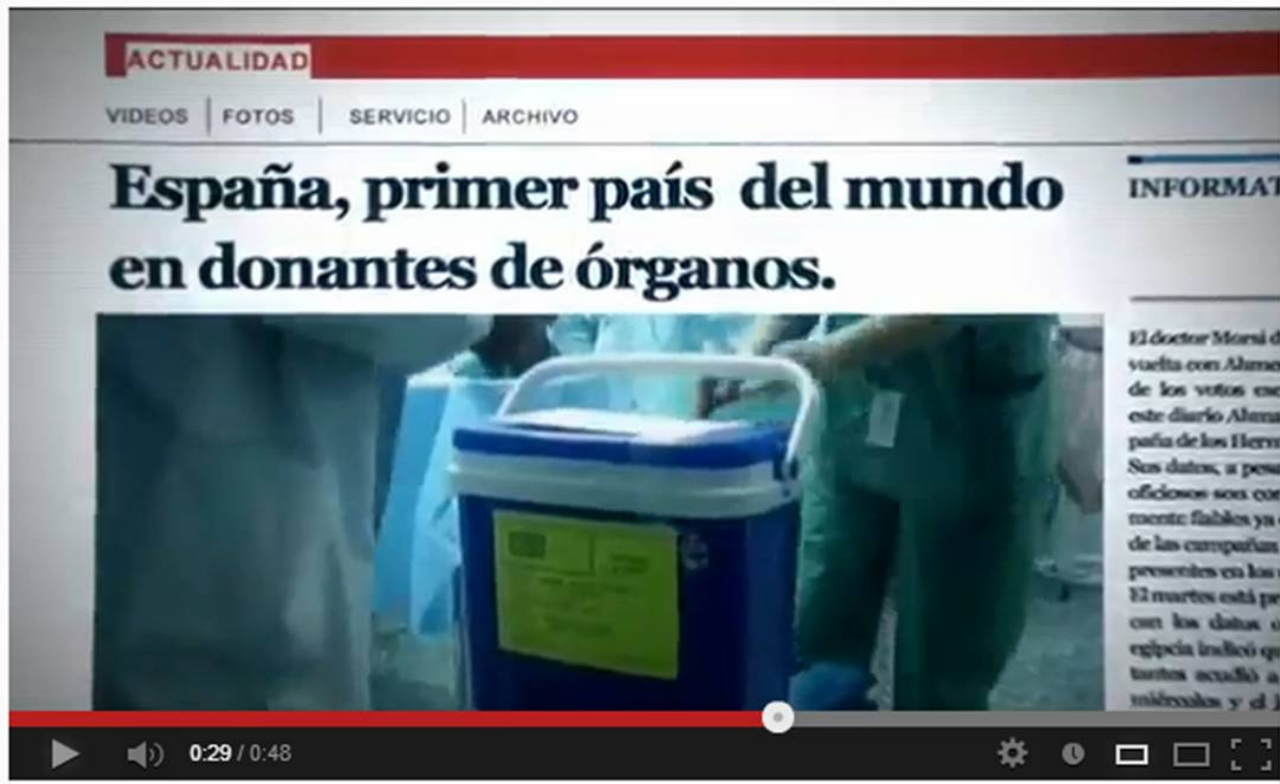

Fuente: imagen obtenida de http://bit.ly/LRYB8m

Otras piezas del mismo anunciante componen lo que podríamos considerar un mosaico de distintas acciones, todas con un nexo de unión en común: el llamamiento a un mundo mejor, generando un efecto viral en redes sociales, como el video "Volvámonos locos" [2] o la acción de street marketing "El cajero de la felicidad".

\subsection{Valores y publicidad}

Tras la multiplicación de la oferta y la demanda, la publicidad dejó de centrar sus mensajes en características racionales y objetivas del producto, para dar paso a otro tipo de discursos en donde conseguir "engagement" por la vía emocional. En este momento de crisis, este hecho se refuerza, aderezado por una proposición de valores como parte del discurso que copa el interés del mismo, especialmente en el medio televisión. La estrategia de posicionamiento, diferenciación y creación ligada a la emoción es una realidad mucho más evidente en la actual coyuntura económica, especialmente en el medio televisión.

Estos mencionados valores pueden ser definidos como los objetivos que identifican a una comunidad, aprendidos en el proceso de socialización, y que inciden significativamente en la conducta.

Maslow propone uno de los enfoques de los valores más conocidos, que supone a su vez las bases de su pirámide motivacional, y que encontramos en su obra "New Knowledge in Human Values" en la década de 1960. Para este autor, los valores son 
referentes de las motivaciones, los instintos y los impulsos, es decir, están directamente relacionados con las necesidades biológicas y psíquicas del hombre y, al igual que éstas, emergen en orden jerárquico.

Rokeach propuso algo más tarde un enfoque distinto de los valores, al entenderlos como estructuras representativas, instrumentos de medida que rigen prescriptivamente la conducta de los individuos al permitirles ordenar e interpretar la realidad, y que son mediatizados por el contexto social, teniendo presente que cada sociedad se encarga de configurarlos y transmitirlos a sus miembros.

En la misma línea, ha surgido en los últimos años una nueva forma de entender los valores que los sitúa en la dimensión del grupo. Es por esto que muchos investigadores han empezado a dejar a un lado la génesis psíquica de las creencias y ha pasado a ocuparse de los colectivos sociales como generadores de valores.

Así, Schwartz (1996) ha desarrollado una tipología de los contenidos de los valores humanos, basándose en la meta motivacional que expresan. Según este autor, los valores representan las respuestas que todos individuos y sociedades deben dar a tres requisitos universales en forma de metas conscientes: las necesidades de los individuos en tanto que organismos biológicos, en tanto que agentes de la interacción social y por tanto necesitados de coordinación, y los requisitos para el correcto funcionamiento de los grupos.

En este sentido, los anuncios publicitarios transmiten y promueven una serie de valores sociales, aspecto que se acentúa en el medio televisión por la variedad de recursos que combina (movimiento, música, imagen, sonido apelación al espectador, mensaje corporativo (claim), actores que actúan de prescriptores, etc.). De esta forma, la carga visual y emocional de los spots hace de la publicidad en televisión un vehículo especialmente eficaz para la transmisión de actitudes y estilos de vida (Méndiz, 2004).

Méndiz (2004) afirma en relación con los orígenes de la investigación sobre publicidad y valores, que los estudios que relacionaban estos dos factores, publicidad y valores culturales, empezaron a comienzos de la década de 1960. Después, a lo largo de casi dos décadas, y en el marco de la revolución cultural que caracterizó a ese período, floreció una investigación muy dispersa, sin unos fundamentos teóricos definidos, y que estaba orientada a la denuncia del imperialismo cultural de occidente. Finalmente, se llegó a un callejón sin salida en el que se pretendía ver la existencia en cualquier elemento de un spot publicitario, de reflejos de culturas dominantes.

En 1986 Richard W. Pollay desarrolló su teoría del "espejo distorsionado", describiendo los valores culturales existentes en los anuncios tras analizar más de 400 campañas de tres países, llegando a identiricar hasta 42 valores transnacionales. Entre las conclusiones más relevantes, cambe destacar como según este estudio, la publicidad no impulsaba por igual los valores de la sociedad en la que se encontraba, sino que se daba una distorsión. De esta forma, la publicidad era, así, un espejo de la sociedad, pero un espejo distorsionado. 
Pollay y Gallagher llevaron a cabo cuatro años más tarde otra investigación, en esta ocasión sobre una muestra de 2000 anuncios publicados en revistas y 250 spots televisivos. Entre las conclusiones, vieron como había una gran consistencia en el tiempo y en los distintos medios acerca de los valores más frecuentemente se promueven en el discurso publicitario. Llegaron a afirmar: "La publicidad refleja sólo determinadas actitudes, conductas y valores. Modela y refuerza solamente ciertos estilos de vida y 'filosofías': aquellos que sirven a los intereses de los vendedores" (Pollay y Gallagher, 1990: 360).

La capacidad de transmisión de valores culturales por parte de la publicidad, en general, podemos afirmar que se ha interpretado de dos formas opuestas: según algunos autores, la publicidad se limita a reflejar fielmente los valores de la sociedad en la que se integra, siendo un mero espejo de la vida social que, como mucho, podría reforzar los valores ya preexistentes; mientras que para otros también contribuye creando tendencias y actitudes y cambiando creencias, debido en parte a su estilo persuasivo y emocional.

En cuanto a los valores sociales, la investigación realizada en los últimos años señala el papel activo de la publicidad a la hora de promoverlos, aunque en ambas perspectivas se asume que la publicidad trata de ser un fiel reflejo de la sociedad de la que forma parte. El fin es activar en el destinatario los mecanismos de identificación y pertenencia, por un lado, y al mismo tiempo servir de catalizador de las motivaciones, aspiraciones y deseos de la sociedad.

Si nos remitimos a nuestro país, hay que señalar que en 1995 Domínguez llevó a cabo un análisis detallado de los valores implícitos en la publicidad televisiva española, tomando en consideración una muestra de 500 anuncios. Podemos considerar tres grandes grupos en el esquema propuesto por Domínguez: los valores del yo (éxito, comodidad, placer, seguridad, etc.), los valores transitivos (amistad, convivencia, servicio, solidaridad, etc.) y los valores colectivos (novedad, juventud, tecnología, progreso, etc.).

\begin{tabular}{|c|l|}
\hline \multirow{5}{*}{ VALORES DEL YO } & 1. Éxito: poder, estimación y autoestima \\
& 2. Confort: comodidad, placer, disfrute \\
& 3. Atracción: belleza y seducción \\
& 4. Notoriedad, lujo, ostentación \\
& 5. Libertad, autonomía, independencia \\
& 6. Seguridad, salud \\
\hline \multirow{5}{*}{ VALORES COLECTIVOS } & 1. Juventud, movimiento y aventura \\
& 2. Novedad, modernidad, moda \\
& 3. Tecnologia, progreso, futuro \\
& 4. Trabajo, esfuerzo \\
& 5. Calidad y tradición \\
\hline \multirow{5}{*}{ VALORES TRANSITIVOS } & 1. Amistad, convivencia \\
& 2. Ternura, amor, cariño \\
& 3. Sentido de comunidad \\
& 4. Servicio, solidaridad \\
5. Ecologia, naturaleza
\end{tabular}

Se pueden ver en la tabla que figura a continuación los valores identificados por Domínguez en torno a estos tres núcleos (tabla $1)$ :

Tabla 1. Tipología de valores.

Fuente: Adaptado de Domínguez (1995)

De acuerdo a esta autora, los valores del yo eran los más frecuentes en publicidad $(57,2 \%)$, seguidos de los valores colectivos $(29,7 \%)$. Ya en última instancia 
aparecían los valores transitivos $(13,1 \%)$. Se constataba así, que la publicidad no refleja todos los valores de una sociedad, sino sólo aquellos que están más vinculados con un estilo de vida consumista, recordando el «espejo distorsionado» de Pollay.

Por su parte Méndiz (2002), corroboró estos mismos resultados en su estudio sobre valores implícitos en la publicidad televisiva, tras basarse en las investigaciones de Pollay (1986), Ai-Ling Liou (1992), Srikandath (1992), Domínguez (1995) y Hong Cheng (1997) [3]. De todos los considerados, el valor más frecuentemente empleado en la publicidad televisiva española, según este estudio, es el de comodidad, confort y facilidad de uso, seguido del placer y el disfrute y de la economía como tercer valor. Por tanto, la publicidad española parece ser un reflejo parcial de la sociedad, al destacar los valores y aspiraciones que apelan a las tendencias más egocéntricas y utilitaristas.

Según esto, podemos concluir con que los valores más relegados en la publicidad televisiva actual son de tres tipos: los que implican responsabilidad personal (competitividad, trabajo y esfuerzo), los de carácter transitivo y altruista (amistad, comprensión) y los más tradicionales (patriotismo, respeto a los mayores, madurez, tradición).

Consideramos también a Alameda (2006: 192-195), quien distingue tres tipos de valores en el discurso publicitario: aquellos valores centrados en las cualidades del producto (comodidad, funcionalidad, confort, ahorro, placer), los valores personales que el consumidor ostentaría mediante la adquisición del producto (diferenciación, calidad de vida, energía-vitalidad, ahorro de tiempo, dinero o esfuerzo, mejora del aspecto físico, etc.) y por último los valores sociales (liderazgo, cohesión familiar, preocupación por los demás).

Así las cosas, podemos concluir, en definitiva, que la publicidad no sólo refleja aquellos valores que afloran en la vida social, sino que al mismo tiempo promueve y difunde también determinados valores. A priori, estos valores son aquellos que definen un estilo de vida consumista, con un marcado materialismo de fondo.

A pesar de que la publicidad sea un espejo distorsionado, el hecho de que la publicidad sea un reflejo de la sociedad nos hace pensar en cómo puede reflejar la actual situación de crisis económica y, sobre todo, qué mensaje y qué valores transmite para hacer frente a ella.

Este es el aspecto que estudiaremos en el trabajo de campo, al analizar valores presentes en una muestra de spot televisivos.

\section{Métodología e hipótesis}

En este estudio el trabajo de campo ha consistido en el análisis del discurso publicitario, en contenido y forma, de una muestra de campañas publicitarias difundidas en televisión entre diciembre de 2012 y febrero de 2013 en España. El fin es identi- 
ficar valores presentes en las estrategias publicitarias de los anunciantes frente a la coyuntura actual, protagonizada por la crisis económica.

Después de haber revisado el marco teórico sobre valores y publicidad, y tomando en consideración la actual coyuntura socioeconómica, nos planteamos estudiar la siguiente hipótesis de manera exploratoria:

La actual y aguda coyuntura económica con la crisis como protagonista, sumada al auge de las redes sociales, con protagonismo absoluto a su vez del usuario, motivan un discurso publicitario centrado en las personas en el que se sustituyen los valores y aspiraciones que apelan a las tendencias más egocéntricas y utilitaristas, por otros de carácter social, altruista y de responsabilidad personal.

A partir de la muestra tomada en consideración, se identifican los valores que aparecen en la historia publicitaria, siguiendo la tipología identificada por Domínguez (1995). Se describen y analizan las siguientes variables: puesta en escena, protagonistas, discurso, melodía, eslogan de la campaña o mensaje corporativo incluidos en el cierre del anuncio y comunicación de la presencia de la marca en redes sociales.

A continuación se puede ver en la siguiente tabla las diez campañas publicitarias que conforman la muestra, con el enlace al spot de televisión analizado (tabla 2):

Tabla 2. Muestra del estudio.

\begin{tabular}{|c|c|c|c|c|}
\hline & Anunciante & Sector & Claim & Enlace a spot \\
\hline 1 & Danone & Alimentación & Practica el Danone & http://hit.ly/NAFGI9 \\
\hline 2 & Banco Santander & Finanzas & Tu banco de confianza & http://bit.ly/XDXkVR \\
\hline 3 & Balay & Electrodomésticos & Por un mundo más cómodo & http://bit.ly/NoZLho \\
\hline 4 & Freixenet & Bebidas & La vida es para celebrarla & http://bit.ly/11jQM4Y \\
\hline 5 & Campofrio & Alimentación & $\begin{array}{l}\text { Que nada ni nadie nos quite nuestra } \\
\text { manera de disfrutar de la vida }\end{array}$ & http://bit.ly/NKh1Mc \\
\hline 6 & Coca-Cola & Bebidas & Destapa la felicidad & http://bit.ly/WLifsS \\
\hline 7 & Nestlé & Alimentación & $\begin{array}{l}\text { Quedarte con lo bueno es estar a gusto } \\
\text { con la vida }\end{array}$ & http://bit.ly/WJ6lcC \\
\hline 8 & ING Direct & Finanzas & Fresh Banking & http:I/bit.ly $/$ Xirtlw \\
\hline 9 & Central Lechera Asturiana & Alimentación & Lo m ejor por naturaleza & http://bit.ly/UR7VOB \\
\hline 10 & Fundación ONCE & Enseñanza & No te rindas nunca & http://bit.ly/NJQEFT \\
\hline
\end{tabular}

Fuente: Elaboración propia.

\section{Resultados}

Como se deriva del análisis de cada uno de los anuncios publicitarios de la muestra, la crisis motiva un discurso publicitario centrado en valores relacionados con el afán de superación y el positivismo, siendo las personas y sus historias las que se convierten en protagonistas del mensaje de las marcas. Como se puede apreciar en 
el gráfico siguiente, atendiendo a la tipología establecida por Domínguez (1995), los valores que predominan en estas campañas son de carácter transitivo y colectivo.

El valor individual de la autoestima supone una excepción que también se ve fuertemente reflejada en la estructura narrativa de la publicidad analizada (gráfico 1):

Gráfico 1. Frecuencia de aparición en la muestra de la tipología de valores de Domínguez (1995).

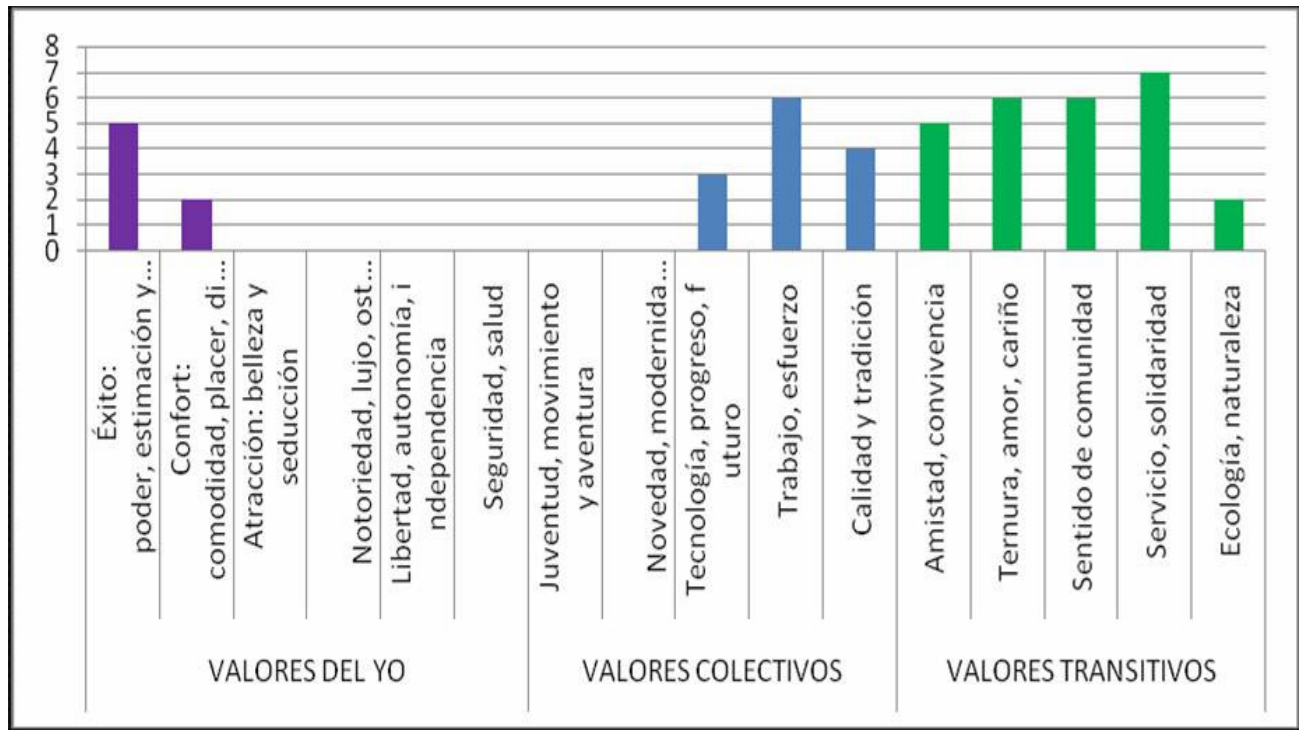

Fuente: Elaboración propia

Sentido de comunidad, solidaridad, esfuerzo, trabajo y ternura, junto a la amistad, son los valores que están presentes en un discurso publicitario, más orientado a la persona que al consumidor (tabla 3 ):

Atendiendo a las variables estudiadas en la muestra de anuncios seleccionados (tabla 4), se observa como los resultados ponen de manifiesto el protagonismo adquirido por las personas en el discurso publicitario, que adquiere un enfoque vocacional y humano, centrado en el destinatario 
Tabla 3. Valores observados en las campañas analizadas.

\begin{tabular}{|c|c|}
\hline Anunciante & Valor es ob servados según la tip ologia de Domínguez (1995) \\
\hline Danone & $\begin{array}{l}\text { Valores del Yo: 2. Disfrute } \\
\text { Valores Colectivos: } 5 \text {. Calidady tradición } \\
\text { Valores Transitivos: } 2 \text {. Ternura, amor, cariño. 3. Sentido de comunidad. } \\
\text { 4. Servicio, solidaridad }\end{array}$ \\
\hline Banco Santander & $\begin{array}{l}\text { Valores del Yo: 1. Exito y autoestima } \\
\text { Valores Colectivos: 3. Futuro, progreso. 4. Trabajo progreso } \\
\text { Valores Transitivos: 1. Amistad, convivencia. 3. Sentido de comunidad. } \\
\text { 4. Servicio, solidaridad }\end{array}$ \\
\hline Bal ay & $\begin{array}{l}\text { Valores Colectivos: 4. Trabajo, esfuerzo. 5. Calidad, tradición } \\
\text { Valores Transitivos: 1. Amistad, convivencia. } 2 \text {. Ternura, amor, cariño. } \\
\text { 4. Servicio, solidaridad }\end{array}$ \\
\hline Freixenet & $\begin{array}{l}\text { Valores del Yo: 1. Exito y autoestima } \\
\text { Valores Colectivos: 4. Trabajo, esfuerzo 5. Calidad y tradición } \\
\text { Valores Transitivos: } 2 \text {. Ternura, amor, cariño. 3. Sentido de comunidad. } \\
\text { 4. Servicio solidaridad }\end{array}$ \\
\hline Campofrio & $\begin{array}{l}\text { Valores del Yo: 1. Éxito y autoestima } \\
\text { Valores Colectivos: 4. Trabajo, esfuerzo. 5. Calidad, tradición } \\
\text { Valores Transitivos: 1. Amistad, convivencia. 3. Sentido de comunidad. } \\
\text { 4. Servicio, solidaridad }\end{array}$ \\
\hline Coca-cola & $\begin{array}{l}\text { Valores Transitivos: 1. Amistad, convivencia. 2. Ternura, amor, cariño. } \\
\text { 3. Sentido de comunidad. 4. Servicio, solidaridad }\end{array}$ \\
\hline Nestlé & $\begin{array}{l}\text { Valores del Yo: 1. Éxito y autoestima } \\
\text { Valores Colectivos: 4. Trabajo, esfuerzo } \\
\text { Valores Transitivos: 2. Ternura, amor, cariño. 3. Sentido de comunidad. } \\
\text { 4. Servicio, solidaridad. 5. Naturaleza, ecologia }\end{array}$ \\
\hline ING Direct & Valores del Yo: 2. Confort: comodidad, placer, disfrute \\
\hline $\begin{array}{l}\text { Central Lechera } \\
\text { Asturiana }\end{array}$ & $\begin{array}{l}\text { Valores del Yo: } 6 \text {. Seguridad, salud } \\
\text { Valores Colectivos: } 3 \text {. Tecnología, progreso, futuro } \\
\text { Valores Transitivos: 1. Amistad, convivencia. 2. Ternura, amor, cariño. } \\
\text { 5. Naturaleza, ecología }\end{array}$ \\
\hline Fundación $\mathrm{ONCE}$ & $\begin{array}{l}\text { Valores del Yo: 1. Éxito y autoestima } \\
\text { Valores Colectivos: 3. Progreso, futuro. 4. Trabajo, esfuerzo }\end{array}$ \\
\hline
\end{tabular}

Fuente: Elaboración propia 
Tabla 4. Variables estudiadas en las campañas seleccionadas.

\begin{tabular}{|c|c|c|c|c|c|c|}
\hline Anunciante & $\begin{array}{c}\text { Puesta en } \\
\text { escena }\end{array}$ & Protagonis-tas & Discurso & Melodía & Cierre & Redes 2.0 \\
\hline Danone & Hogar & Familia & $\begin{array}{l}\text { Positivo, } \\
\text { humanoy } \\
\text { nostálgico }\end{array}$ & $\begin{array}{l}\text { «Let it be» } \\
\text { The Beatles }\end{array}$ & «Practica el danone» & No \\
\hline $\begin{array}{c}\text { Banco } \\
\text { Santander }\end{array}$ & Urbana & $\begin{array}{l}\text { Profesionales, } \\
\text { estudiantes, } \\
\text { trabajadores, } \\
\text { población en } \\
\text { general -muy } \\
\text { heterogéneo- }\end{array}$ & $\begin{array}{l}\text { Positivo, } \\
\text { humano }\end{array}$ & $\begin{array}{c}\text { Música } \\
\text { instrumental }\end{array}$ & $\begin{array}{c}\text { «Tu banco de } \\
\text { confianza» } \\
\text { «Queremos ser tu } \\
\text { banco» } \mathrm{y} \ll \mathrm{E} 1 \text { valor de } \\
\text { las ideas» }\end{array}$ & No \\
\hline Balay & $\begin{array}{c}\text { Laboral y de } \\
\text { ocio }\end{array}$ & $\begin{array}{c}\text { Trabajadores de } \\
\text { Balay }\end{array}$ & $\begin{array}{c}\text { Positivo, } \\
\text { humano, de } \\
\text { agradecimiento }\end{array}$ & \begin{tabular}{|c|} 
Música \\
especifica para \\
la campaña. \\
Letra coherente \\
con el discurso
\end{tabular} & $\begin{array}{c}\text { «Por un mundo más } \\
\text { cómodo» }\end{array}$ & Si \\
\hline Freixenet & $\begin{array}{l}\text { Doble: } \\
\text { teatro y } \\
\text { entornos } \\
\text { diversos }\end{array}$ & $\begin{array}{l}\text { Burbuja } \\
\text { Freixenet e } \\
\text { individuos } \\
\text { anónimos }\end{array}$ & $\begin{array}{c}\text { Positivo, } \\
\text { humano, de } \\
\text { agradecimiento }\end{array}$ & $\begin{array}{c}\text { Música } \\
\text { instrumental }\end{array}$ & $\begin{array}{c}\text { «La vida es para } \\
\text { celebrarla» }\end{array}$ & Sí \\
\hline Campofrio & $\begin{array}{l}\text { Urbano y } \\
\text { doméstico }\end{array}$ & $\begin{array}{c}\text { Fofito, cómicos, } \\
\text { actores, } \\
\text { periodistas y } \\
\text { deportistas } \\
\text { españoles }\end{array}$ & Positivo & $\begin{array}{c}\text { Pasodoble } \\
\text { «uspiros de } \\
\text { España» }\end{array}$ & $\begin{array}{c}\text { «El curriculum de } \\
\text { todos» y } \ll \text { Que nada ni } \\
\text { nadie nos quite nuestra } \\
\text { manera de disfrutar la } \\
\text { vida» }\end{array}$ & Sí \\
\hline Coca-cola & Urbano & $\begin{array}{l}\text { Población en } \\
\text { general. Muy } \\
\text { heterogéneo e } \\
\text { internacional }\end{array}$ & $\begin{array}{l}\text { Positivo y } \\
\text { altruista }\end{array}$ & & $\begin{array}{l}\text { «Miremos el nuevo } \\
\text { año con \#positividad» } \\
\text { y «Destapa la } \\
\text { felicidad» }\end{array}$ & Sí \\
\hline Nestlé & $\begin{array}{l}\text { Laboral y } \\
\text { rural }\end{array}$ & $\begin{array}{c}\text { Trabajadores de } \\
\text { Nestlé }\end{array}$ & $\begin{array}{l}\text { Positivo y } \\
\text { humano }\end{array}$ & $\begin{array}{c}\text { «T ear in her } \\
\text { eye» de } \\
\text { Duncan Faure }\end{array}$ & $\begin{array}{c}\text { «Quedarte con lo } \\
\text { bueno es estar a gusto } \\
\text { con la vida» }\end{array}$ & No \\
\hline ING Direct & Neutro & Nadie & No intrusivo & $\begin{array}{c}\text { «Crimson and } \\
\text { Clover» de } \\
\text { Tommy James } \\
\text { \& The } \\
\text { Sondalle } \\
\end{array}$ & $\begin{array}{c}\text { «Pensar» } \mathrm{y} \ll \text { Fresh } \\
\text { Banking» }\end{array}$ & No \\
\hline $\begin{array}{c}\text { Central } \\
\text { Lechera } \\
\text { Asturiana } \\
\end{array}$ & $\begin{array}{c}\text { Rural, } \\
\text { doméstica y } \\
\text { educativa } \\
\end{array}$ & Niños & $\begin{array}{l}\text { Positiv o y de } \\
\text { futuro }\end{array}$ & & $\begin{array}{l}\text { «Lo mejor por } \\
\text { naturaleza» }\end{array}$ & Sí \\
\hline $\begin{array}{c}\text { Fundación } \\
\text { ONCE }\end{array}$ & Urbano & $\begin{array}{l}\text { Jóvenes con } \\
\text { discapacidad }\end{array}$ & $\begin{array}{c}\text { Motivador y de } \\
\text { superación }\end{array}$ & $\begin{array}{c}\text { Música } \\
\text { instrumental }\end{array}$ & «No te rindas nunca» & Sí \\
\hline
\end{tabular}

Fuente: Elaboración propia 
Si tomamos en consideración los mensajes corporativos, en cinco casos apelan al destinatario, tres de ellos de manera clara empleado un imperativo ("Practica el Danone", "Destapa la felicidad" y "No te rindas nunca"); otro haciendo uso de un infinitivo que se refiere también al usuario ("Quedarte con lo bueno es estar a gusto con la vida") y un quinto que se refiere a la empresa, pero conectando con el destinatario al usar el posesivo ("Tu banco de confianza"). Hemos considerado que un sexto mensaje corporativo no utiliza la apelación al destinatario porque utiliza un plural y un posesivo en primera persona del plural, que implican colectividad, pero su estructura sí denota una petición u obligación para la audiencia del mensaje: "Que nada ni nadie nos quite nuestra manera de disfrutar de la vida".

Destacar también que tres de los otros lemas son discursos en primera persona, centrados en la empresa y su voluntad de servicio: "Por un mundo más cómodo", "Fresh Banking" y "Lo mejor por naturaleza". Únicamente en el caso de Freixenet no se habla de la empresa, ni se apela al destinatario, pero sí es un llamamiento al incidir en el claim "La vida es para celebrarla".

Se puede apreciar como los spots analizados utilizan una puesta en escena cotidiana y cercana, real, a excepción del caso de Freixenet o de ING Direct. El discurso utilizado es fundamentalmente positivo, humano y motivador, reforzado por una melodía coherente y acorde al discurso planteado.

Tomando en consideración el fondo y la forma del discurso empleado en estas campañas, observamos cómo éste se fundamenta en la idea del cambio, la confianza y la autoestima. Casi con un juego de palabras, podemos concluir que el mensaje se basa en que no hay mejor forma de hacer que las cosas cambien que cambiar nosotros mismos nuestra forma de ver las cosas.

Es importante destacar cómo las marcas no se dirigen a consumidores, se dirigen a personas, y optan por hacer el ejercicio de ponerse en el lugar de cada uno de nosotros, haciendo un guiño en sus mensajes publicitarios a la situación económica, y al mismo tiempo dando un mensaje de optimismo, seguridad, comprensión, confianza e ilusión, que en ocasiones se disfraza con pinceladas de humor. De esta forma, la publicidad está asumiendo un papel de animador social, involucrándose con el ciudadano ante la crisis de confianza que acompaña a la crisis económica.

Además, en los spots analizados la presencia de las redes sociales, mediante la comunicación de los canales de la marca en plataformas sociales o el uso de etiquetas de Twitter (hashtags), es significativa, por lo que se fomenta una comunicación multicanal más allá del spot publicitario, es decir, una comunicación de marketing integrada (IMC). 


\section{Conclusiones y discusión}

A la vista de los resultados de esta investigación y tomando al mismo tiempo en consideración los estudios previos aquí señalados en el marco teórico, se puede concluir que en los años previos a la crisis económica en España -años de bonanza económica- se constataba un uso destacado de aspiraciones y valores y se apelaba a su vez a tendencias egocéntricas y utilitaristas, quedando muy relegados los valores de carácter transitivo y altruista (amistad, comprensión), los más tradicionales (patriotismo, respeto a los mayores, madurez, tradición) y los que implican responsabilidad personal (competitividad, trabajo y esfuerzo)

La publicidad en este sentido, por tanto, no reflejaba todos los valores de una sociedad, sino sólo aquellos que están más vinculados con un estilo de vida consumista, recordando el espejo distorsionado de Pollay.

Podemos concluir como los datos obtenidos confirman la hipótesis de partida: el discurso publicitario, en un contexto de crisis económica y auge de las redes sociales, se centra en las personas, sustituyendo, como hemos señalado, aquellos valores que apelan a tendencias egocéntricas y utilitaristas, por otros de carácter social, altruista y de responsabilidad personal.

La expansión de las redes sociales influye en un discurso publicitario, el cual busca la empatía con el destinatario, al mismo tiempo que intenta hacer un llamamiento a los valores humanos como estrategia de comunicación frente a la crisis económica.

La publicidad utiliza mecanismos que activan la identificación y la sensación de pertenencia del receptor, catalizando motivaciones, deseos y aspiraciones de la sociedad, y desempeñando un papel activo a la hora de promover nuevos valores sociales.

Los anuncios analizados ya no apelan tanto a necesidades fisiológicas (materialistas) de los individuos, como a aquellas más sociales (postmaterialistas), de sentido de pertenencia a una sociedad menos impersonal, fomento de la convivencia y de la autoestima, ensalzando el valor de las personas.

Tal y como afirma Hellín (2007: 248), "la vigencia de los valores en una sociedad se halla sometida a diversas condiciones de tipo económico, educacional, laboral, político, etc.”, como puede ser una crisis económica, que fomenta el llamamiento a valores de generación de comunidad y afán de superación. Sumamos a esta reflexión que, en efecto, la publicidad es reflejo de este cambio de valores, influido por condicionantes externos, como se ha podido apreciar en la muestra de anuncios analizada.

En suma, la publicidad cada vez más recurre a la emocionalidad y, ante situaciones negativas, fomenta el positivismo, el afán de superación, así como el sentimiento de unión entre individuos o pertenencia a un grupo, el esfuerzo personal, el compromiso social, la preparación para el futuro y la autorrealización de la persona.

De esta forma, lo expuesto no es más que un ejemplo de que la publicidad hace tiempo que pasó de ser una exclusiva herramienta comercial de las empresas a ser una forma de racionalidad utilizada en la sociedad como argumento legitimador de 
comportamientos y estilos de vida, compartiendo valores, formulando experiencias y prescribiendo comportamientos sociales y estilos de vida (Benavides, 2012: 83). Como también continúa Benavides, la publicidad es una "industria cultural que utiliza sus herramientas y recursos comunicativos no sólo en la promoción comercial de productos y servicios sino en la construcción y legitimación de discursos sociales que afectan a la vida de las personas".

Como futuras líneas de investigación, podríamos apuntar aquellas que se centran en ampliar la muestra de estudio con el fin de corroborar la tendencia en el uso de valores relacionados con el sentido de comunidad y el afán de superación en el discurso publicitario en el contexto de crisis económica. De la misma forma, otro estudio complementario podría analizar la interacción y la participación que se generan en los medios sociales de las empresas, marcas y productos de estas campañas publicitarias, en especial el uso de las etiquetas en Twitter.

\section{Referencias bibliográficas}

ALAMEDA, D. (2006). Una nueva realidad publicitaria: la generación de valores corporativos en publicidad. Madrid: Laberinto.

BENAVIDES DELGADO, J. (2012). "La investigación en comunicación y publicidad". En: Questiones Publicitarias, vol. I, n 17. p. 71-93. Disponible en: http:// bit.ly/VJSTx4. [20-02-2013].

BRYANT, J.; MIRON, D. (2004). "Theory and Research in Mass Communication". En: Journal of Communication, LIV, no 4. p. 662-704.

CARO ALMELA, A. (2009). "Publicidad y crisis capitalista". En: Pensar la publicidad: revista internacional de investigaciones publicitarias, vol. III, $\mathrm{n}^{\mathrm{o}}$ 1. p. 9-14. Disponible en: http://revistas.ucm.es/index.php/PEPU/article/view/ PEPU0909120009A/15414. [10-01-2013].

DEL PINO, C.; CASTELLÓ, A.; RAMOS-SOLER, I. (2013). La comunicación en cambio constante. Branded Content, Community Management, Comunicación 2.0 y Estrategia en medios sociales. Madrid: Fragua.

DOMINGUEZ, L. (1995). Publicidad y Valores. Modelos de consumidor y análisis de valores en la publicidad televisiva actual. Tesis Doctoral en Comunicación Pública. Pamplona: Universidad de Navarra.

FERNÁNDEZ BLANCO, E.; ALAMEDA GARCÍA, D.; MARTÍN MARTÍN, I. (2011). "Las estrategias publicitarias de las marcas en el contexto de crisis". En: AdComunica: revista científica de estrategias, tendencias e innovación en comunicación, $\mathrm{n}^{\mathrm{o}}$ 1. p. 119-138. Disponible en: http://www.adcomunicarevista.com/ojs/ index.php/adcomunica/article/view/12. [12-01-2013].

HELLÍN ORTUÑO, P. (2007). Publicidad y valores posmodernos. Madrid: Siranda Editorial.

MARSHALL, P. (2004). New Media Cultures. Londres: Arnold Publishers. 
MÉNDIZ NOGUERO, A. (dir.) (2004). "Publicidad, educación y nuevas tecnologías". Serie Informes $\mathrm{n}^{\mathrm{o}}$ 12. Madrid: CNICE-Ministerio de Educación y Ciencia. Disponible en: http://ares.cnice.mec.es/informes/12/contenido/indice.htm. [12-022013].

MÉNDIZ NOGUERO, A. (2002). "Publicidad y valores: criterios para una adecuada valoración”. En AGEJAS, J.A.; SERRANO, F.J. Ética de la comunicación y de la información. Barcelona: Ariel Comunicación. p. 217-242.

MONTERO RIVERO, Y. (2006). Televisión, valores y adolescencia. Madrid: Gedisa. POLLAY, R.; GALLAGHER, K. (1990). "Advertising and Cultural Values: reflections in the Distorted Mirror". En: Internatinal Journal of Adverstising, $\mathrm{n}^{\mathrm{o}}$ 9. $\mathrm{p}$. 359-372.

POLLAY, R. (1986). "The distorted mirror: reflections on the unintended consequences of advertising". En: Journal of Marketing, vol. II, $\mathrm{n}^{\circ}$ 50. p. 18-36.

- (1983). "Measuring the Cultural Values Manifest in Advertising". En LEIGH, J. H.; MARTIN, C. R. (ed.). Current Issues and Research in Advertising. Ann Arbor: University of Michigan. p. 71-92.

SCHWARTZ, S. (1996). "Value priorities and behaviour: applying a theory of integrated value systems". En SELINGMAN, C.; OLSON, J.; ZANNA, M. (ed.) The psychology of values: The Ontaryo Symposium, VIII. Mahwah (New Jersey): Lawrence Erlbaum Associates. p. 1-24.

\section{NOTAS}

[1] Se puede ver el anuncio en: http://bit.ly/15ZVqY.

[2] Se puede consultar en: http://bit.ly/VMSeUo.

[3] Puede verse el listado de los 39 valores identificados en: http://ares.cnice.mec.es/informes/12/ contenido/pagina $\% 20144 . h t m$.

\section{Las autoras}

Araceli Castelló Martínez. Doctora en Comunicación, Máster en Comunicación Integral, Máster Ejecutivo en Community Management y Licenciada en Publicidad y RR.PP., con premio extraordinario de Licenciatura y segundo premio nacional. Imparte docencia en los estudios de Publicidad y RR.PP. en la Universidad de Alicante y colabora como profesora en diversos postgrados. Ha trabajado en agencias de medios y soportes digitales en España y Bélgica y realizado numerosas publicaciones sobre planificación publicitaria y marketing en medios sociales. Dirige el Observatorio Comunicación En Cambio (www.comunicacionencambio.com). Más información en www.aracelicastello.com. 
Irene Ramos Soler. Doctora en Sociología por la Universidad de Alicante, donde desempeña su labor docente e investigadora en el área de Comunicación Audiovisual y Publicidad desde el año 2000. Su tarea investigadora se centra en el estudio de las relaciones de la comunicación con diferentes públicos, participando en diferentes proyectos de investigación $(\mathrm{I}+\mathrm{D}+\mathrm{i})$. Coordinadora del seminario permanente de investigación "Observatorio Mayores y Medios de Comunicación" de la Universidad de Alicante y directora del Grupo de Investigación "Comunicación y Públicos Específicos". Sus contribuciones han sido publicadas en diferentes libros y revistas científicas, así como en congresos nacionales e internacionales.

Cristina Del Pino Romero. Doctora en Ciencias de la Información (Universidad de Málaga, 2004) con una tesis basada en el brand placement. Ha impartido asignaturas de Publicidad y RR.PP. en la Universidad de Alicante (2000-2006) y ha sido profesora visitante en el Departamento de Comunicación de UCLA (Los Ángeles, 2009). Actualmente es profesora de Comunicación Publicitaria y Periodística, Nuevas Formas Publicitarias y Advertising and Communication en la Universidad Carlos III de Madrid. Es autora de los libros "Brand Placement: integración de las marcas en la ficción audiovisual" (Gedisa, 2006), "Marcas y Ficción Televisiva" (Icono 14, 2013) y "La Comunicación en Cambio Constante" (Fragua, 2013). 